\title{
Influence of particle characteristics on granular friction
}

\author{
Jennifer L. Anthony ${ }^{1}$ and Chris Marone \\ Rock Mechanics Laboratory, Department of Geosciences, Pennsylvania State University, University Park, Pennsylvania,
} USA

Received 23 August 2004; revised 15 April 2005; accepted 19 May 2005; published 19 August 2005.

[1] We report on laboratory experiments designed to illuminate grain-scale deformation mechanisms within fault gouge. We vary particle size distribution, grain and surface roughness, and gouge layer thickness to better understand how grain sliding, rolling, dilation, and compaction affect the strength and stability of granular fault gouge. The experiments employed the double direct shear testing geometry and were run at room temperature, controlled humidity, and shearing rates from 0.1 to $3000 \mu \mathrm{m} / \mathrm{s}$. Experiments were carried out under constant normal stress of 5 and $10 \mathrm{MPa}$ and thus within a nonfracture loading regime where sliding friction for smooth, spherical particles is measurably lower than for rough, angular particles. We compare results from shear between smooth boundaries, where we hypothesize that grain boundary sliding is the dominant deformation mechanism, and roughened surfaces, where rolling and granular dilation contribute to shear deformation. We find that particle angularity and bounding surface roughness increase the frictional strength within sheared layers, indicating differences in particle reorganization due to these factors. In gouge material composed of $<30 \%$ angular grains we observe repetitive stick-slip sliding where stress drop decreases while preinstability creep increases with increasing gouge layer thickness. Our data show significant differences in stick-slip characteristics as a function of gouge layer thickness and particle size, which we interpret in terms of the mechanics of grain bridges that support forces on the layers. We suggest that force chains exhibit qualitative differences as a function of grain angularity and bounding surface roughness.

Citation: Anthony, J. L., and C. Marone (2005), Influence of particle characteristics on granular friction, J. Geophys. Res., 110, B08409, doi:10.1029/2004JB003399.

\section{Introduction}

[2] Natural faults produce granular wear material continuously as a function of shear and grinding between the slipping surfaces. The wear material, known as fault gouge, varies in mineral composition, particle size, and thickness depending on the geologic setting and factors that determine the balance between the wear/disaggregation rate and the lithification/consolidation rate. In general, the fault zone frictional properties are governed by material properties and structure of the gouge zone, including fabric development and degree of shear localization. The characteristics of fault gouge have been studied extensively in the field, laboratory, and numerical simulations in order to gain a better understanding of fault mechanics [e.g., Engelder, 1974; Chester and Logan, 1986; Reches, 1988; Biegel et al., 1989; Marone and Scholz, 1989; Scott et al., 1994; Evans and Chester, 1995; Chester and Chester, 1998; Mora and Place, 1998, 1999; Morgan and Boettcher, 1999; Morgan, 1999; Aharonov and Sparks, 1999; Katz et al., 2003]; however, there are still many unanswered questions

\footnotetext{
${ }^{1}$ Now at ExxonMobil Exploration Company, Houston, Texas, USA.
}

Copyright 2005 by the American Geophysical Union. 0148-0227/05/2004JB003399\$09.00 about the role that gouge material plays in determining fault strength and stability.

[3] Generally, as active faults accumulate slip, gouge zones thicken and shear localizes along microstructures within the gouge layer [e.g., Scholz, 1987; Marone, 1998]. The gouge material and surface roughness of the country rock can affect the degree of localization within shear zones [Mühlhaus and Vardoulakis, 1987; Biegel et al., 1989, 1992; Marone et al., 1992; Sammis and Steacy, 1994; Scott et al., 1994]. Although shear fabrics have been well documented in the field and produced in the laboratory [Logan et al., 1979; Sammis et al., 1986; Marone and Scholz, 1989; An and Sammis, 1994; Beeler et al., 1996; Chester and Chester, 1998; Mair and Marone, 1999; Mair et al., 2002], the effects of grain characteristics and bounding surface roughness on the development of shear zones are not well understood. Granular material can accommodate strain through grain communition, dilation, compaction, sliding, rotating, and/or rolling. Previous work has shown that shear localization increases with displacement for both rough and smooth bounding surfaces [Marone et al., 1992; Sammis and Steacy, 1994]. We compare results from shear between smooth boundaries, where we hypothesize that grain boundary sliding is the dominant deformation mechanism, and roughened surfaces, where shear undergoes a transition from pervasive to progressively 


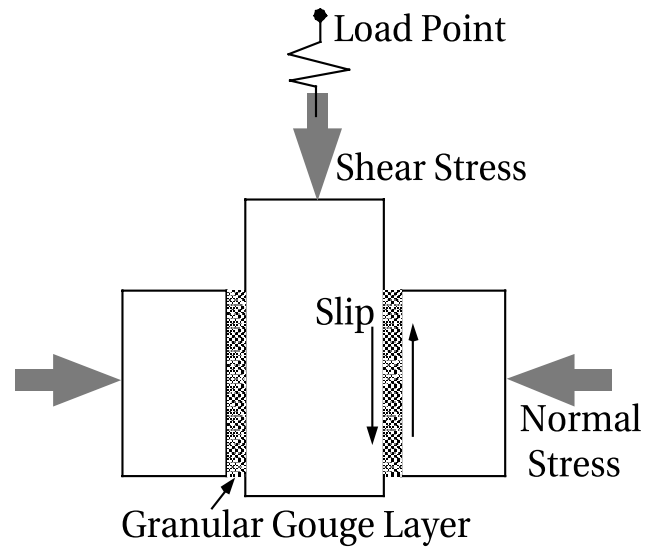

Figure 1. Diagram of double direct shear sample configuration. Granular gouge layers $(2-8 \mathrm{~mm}$ thick) are driven between roughened or smooth steel blocks. Nominal frictional contact area is $10 \times 10 \mathrm{~cm}^{2}$. Normal stress is applied horizontally as the center block is driven down between the two stationary side blocks, which are supported from below, to create frictional shear and slip within the gouge layer. localized shear as a function of increasing net strain. We also examine the effects of grain angularity on the frictional strength of sheared layers. Mair et al. [2002] show that the presence of angular grains not only increases friction in shear zones but also promotes stable sliding. Other studies in granular mechanics also find that particle shape and bounding surface roughness influence the behavior and strength of granular media [Jensen et al., 1999; Mueth et al., 2000; Albert et al., 2001; Nouguier-Lehon et al., 2003].

[4] In our experiments we observe both stable sliding and repetitive stick-slip behavior. Unstable stick-slip behavior has been observed in both rock-on-rock and granular gouge friction experiments [e.g., Engelder et al., 1975; Dieterich, 1978; Tullis, 1988; Wong and Zhao, 1990; Berman et al., 1996; Karner and Marone, 2000; Mair et al., 2002]. Gouge material that slides unstably is thought to deform by the continuous development and failure of force chains [Biegel et al., 1989; Sammis and Steacy, 1994; Cates et al., 1998; Morgan and Boettcher, 1999; Mair et al., 2002].

[5] The purpose of this paper is to investigate how fault surface roughness and gouge particle characteristics such as shape, roughness, and size affect the frictional strength,

Table 1. Experiment Parameters

\begin{tabular}{|c|c|c|c|c|c|c|c|}
\hline Experiment & $\begin{array}{c}\text { Forcing } \\
\text { Block Surface } \\
\end{array}$ & $\begin{array}{c}\text { Gouge } \\
\text { Composition }\end{array}$ & $\begin{array}{c}\text { Initial Gouge } \\
\text { Thickness, mm }\end{array}$ & $\begin{array}{c}\text { Grain } \\
\text { Diameter, } \mu \mathrm{m} \\
\end{array}$ & $\begin{array}{c}\text { Normal } \\
\text { Stress, MPa }\end{array}$ & $\begin{array}{c}\text { Velocity } \\
\text { Range, } \mu \mathrm{m} / \mathrm{s}\end{array}$ & Sliding \\
\hline p191S3gr010 & rough & glass beads & 3 & $53-74$ & 10 & $0.1-3000$ & stick-slip \\
\hline p429S3gr010 & rough & glass beads & 3 & $62-105$ & 10 & $0.1-300$ & stick-slip \\
\hline p132S3gr010 & rough & glass beads & 3 & $74-105$ & 10 & $1-100$ & stick-slip \\
\hline p134S7gr010 & rough & glass beads & 7 & $74-105$ & 10 & $6-300$ & stick-slip \\
\hline p135S3gr010 & rough & glass beads & 3 & $74-105$ & 10 & $6-300$ & stick-slip \\
\hline p175S3gr010 & rough & glass beads & 3 & $74-105$ & 10 & $0.1-3000$ & stick-slip \\
\hline p137S3gr010 & rough & glass beads & 3 & $74-105$ & 10 & $6-300$ & stick-slip \\
\hline p168S5gr010 & rough & glass beads & 5 & $74-210$ & 10 & $3-300$ & stick-slip \\
\hline p174S3gr010 & rough & glass beads & 3 & $74-210$ & 10 & $0.1-3000$ & stick-slip \\
\hline p138S3gr010 & rough & glass beads & 3 & $53-210$ & 10 & $6-300$ & stick-slip \\
\hline p180S3gr010 & rough & glass beads & 3 & $53-210$ & 10 & $0.1-3000$ & stick-slip \\
\hline p428S3gr010 & rough & glass beads & 3 & $105-149$ & 10 & $0.1-300$ & stick-slip \\
\hline p192S3gr010 & rough & glass beads & 3 & $210-297$ & 10 & $0.1-3000$ & stick-slip \\
\hline p431S3gr010 & rough & glass beads & 3 & $250-297$ & 10 & $0.1-300$ & stick-slip \\
\hline p437S3gr010 & rough & glass beads & 3 & $508-590$ & 10 & $0.1-300$ & stick-slip \\
\hline p171S3gr010 & rough & $90 / 10$ glass beads & 3 & $50-150$ & 10 & $3-3000$ & stick-slip \\
\hline $\mathrm{p} 155 \mathrm{~S} 5 \mathrm{mr} 010$ & rough & $90 / 10$ glass beads/F110 & 5 & $50-150$ & 10 & $3-300$ & stick-slip \\
\hline p156S7mr010 & rough & $90 / 10$ glass beads/F110 & 7 & $50-150$ & 10 & $3-100$ & stick-slip \\
\hline $\mathrm{p} 176 \mathrm{~S} 3 \mathrm{mr} 010$ & rough & $90 / 10$ glass beads/F110 & 3 & $50-150$ & 10 & $0.1-3000$ & stick-slip \\
\hline p159S3mr010 & rough & $80 / 20$ glass beads/F110 & 3 & $50-150$ & 10 & $0.1-3000$ & stable/stick-slip \\
\hline $\mathrm{p} 177 \mathrm{~S} 3 \mathrm{mr} 010$ & rough & $80 / 20$ glass beads/F110 & 3 & $50-150$ & 10 & $0.1-3000$ & stable/stick-slip \\
\hline $\mathrm{p} 161 \mathrm{~S} 3 \mathrm{mr} 010$ & rough & $70 / 30$ glass beads/F110 & 3 & $50-150$ & 10 & $0.1-3000$ & stable \\
\hline $\mathrm{p} 178 \mathrm{~S} 3 \mathrm{mr} 010$ & rough & $70 / 30$ glass beads/F110 & 3 & $50-150$ & 10 & $0.1-3000$ & stable \\
\hline p172S3mr010 & rough & $60 / 40$ glass beads/F110 & 3 & $50-150$ & 10 & $0.1-3000$ & stable \\
\hline $\mathrm{p} 179 \mathrm{~S} 3 \mathrm{mr} 010$ & rough & $50 / 50$ glass beads/F110 & 3 & $50-150$ & 10 & $0.1-3000$ & stable \\
\hline $\mathrm{p} 181 \mathrm{~S} 3 \mathrm{mr} 010$ & rough & F110 quartz & 3 & $50-150$ & 10 & $0.1-3000$ & stable \\
\hline p194S3gs005 & smooth & glass beads & 3 & $53-210$ & 5 & $0.1-300$ & stable \\
\hline p268S3gs005 & smooth & glass beads & 3 & $74-105$ & 5 & $0.1-300$ & stable \\
\hline $\mathrm{p} 242 \mathrm{~S} 3 \mathrm{gs} 005$ & smooth & glass beads & 3 & $105-149$ & 5 & $0.1-300$ & stable \\
\hline $\mathrm{p} 260 \mathrm{~S} 3 \mathrm{gs} 005$ & smooth & glass beads & 3 & $105-149$ & 5 & $0.1-300$ & stable \\
\hline $\mathrm{p} 267 \mathrm{~S} 3 \mathrm{gs} 005$ & smooth & glass beads & 3 & $105-149$ & 5 & $0.1-300$ & stable \\
\hline $\mathrm{p} 272 \mathrm{~S} 3 \mathrm{gs} 005$ & smooth & glass beads & 3 & $150-210$ & 5 & $0.1-300$ & stable \\
\hline $\mathrm{p} 266 \mathrm{~S} 3 \mathrm{~ms} 005$ & smooth & $50 / 50$ glass beads/F110 & 3 & $50-150$ & 5 & $0.1-300$ & stable \\
\hline $\mathrm{p} 274 \mathrm{~S} 3 \mathrm{mr} 005$ & smooth & F110 quartz & 3 & $50-150$ & 5 & $0.1-300$ & stable \\
\hline p292S3gr005 & rough & glass beads & 3 & $74-105$ & 5 & $0.1-300$ & stick-slip \\
\hline p283S3gr005 & rough & glass beads & 3 & $74-105$ & 5 & $0.1-300$ & stable/stick-slip \\
\hline p442S2gr005 & rough & glass beads & 2 & $105-149$ & 5 & $0.1-300$ & stick-slip \\
\hline p275S3gr005 & rough & glass beads & 3 & $105-149$ & 5 & $0.1-300$ & stick-slip \\
\hline p440S5gr005 & rough & glass beads & 5 & $105-149$ & 5 & $0.1-300$ & stick-slip \\
\hline p441S8gr005 & rough & glass beads & 8 & $105-149$ & 5 & $0.1-300$ & stick-slip \\
\hline p289S3gr005 & rough & glass beads & 3 & $150-210$ & 5 & $0.1-300$ & stick-slip \\
\hline $\mathrm{p} 279 \mathrm{~S} 3 \mathrm{mr} 005$ & rough & $50 / 50$ glass beads/F110 & 3 & $50-150$ & 5 & $0.1-300$ & stable \\
\hline p294S3mr005 & rough & F110 quartz & 3 & $50-150$ & 5 & $0.1-300$ & stable \\
\hline
\end{tabular}




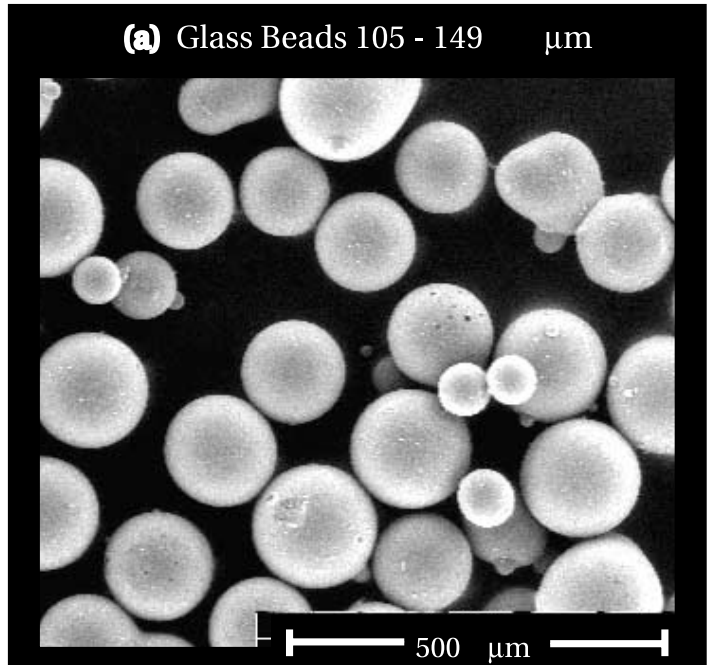

(b) $50 \%$ f110 Quartz / 50\% Glass Beads

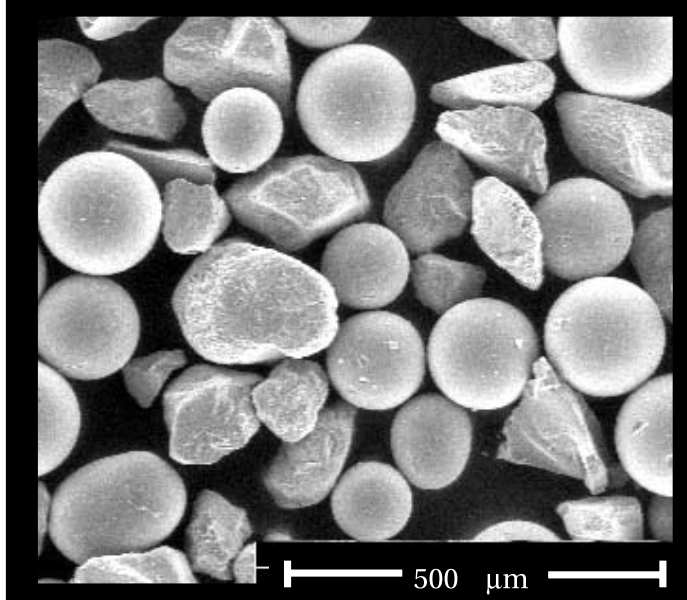

(C) f110 Quartz 50 - $150 \quad \mu \mathrm{m}$

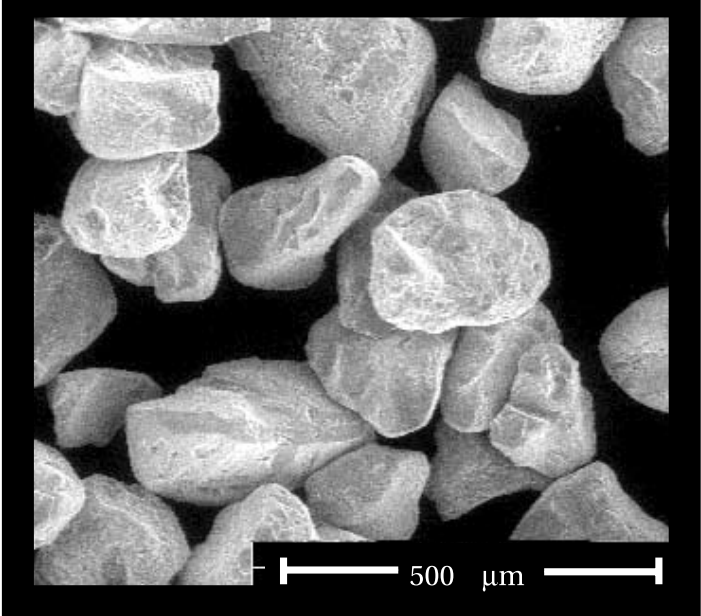

Figure 2. Scanning electron microscope (SEM) photomicrographs of undeformed gouge. (a) Spherical glass beads, particle size distribution 105-149 $\mu \mathrm{m}$ (diameter). (b) Gouge mixture by weight, $50 \%$ spherical glass beads, $50 \%$ angular quartz. (c) F110 angular quartz, particle size distribution $50-150 \mu \mathrm{m}$ (diameter). stability, and degree of shear localization within granular shear zones. The granular layers are sheared at various rates throughout an experiment and under conditions where grain fracture is minimal. Our data indicate systematic changes in frictional strength and stability as a function of particle surface roughness and the percentage of angular grains within a gouge layer. During unstable sliding we document changes in stress drop, preseismic slip, recurrence interval, and compaction as a function of loading velocity, gouge layer thickness, and particle size and angularity. Our results show that there are first-order differences in frictional characteristics due to the shape, size, and number of grains across gouge layers.

\section{Experiment Procedure}

[6] All laboratory experiments were performed using a servohydraulic double direct shear testing apparatus. This assembly includes three rigid forcing blocks with two gouge layers sandwiched between rough or smooth surfaces of the blocks (Figure 1). The blocks are held in place by applying a constant horizontal normal force that is maintained by a

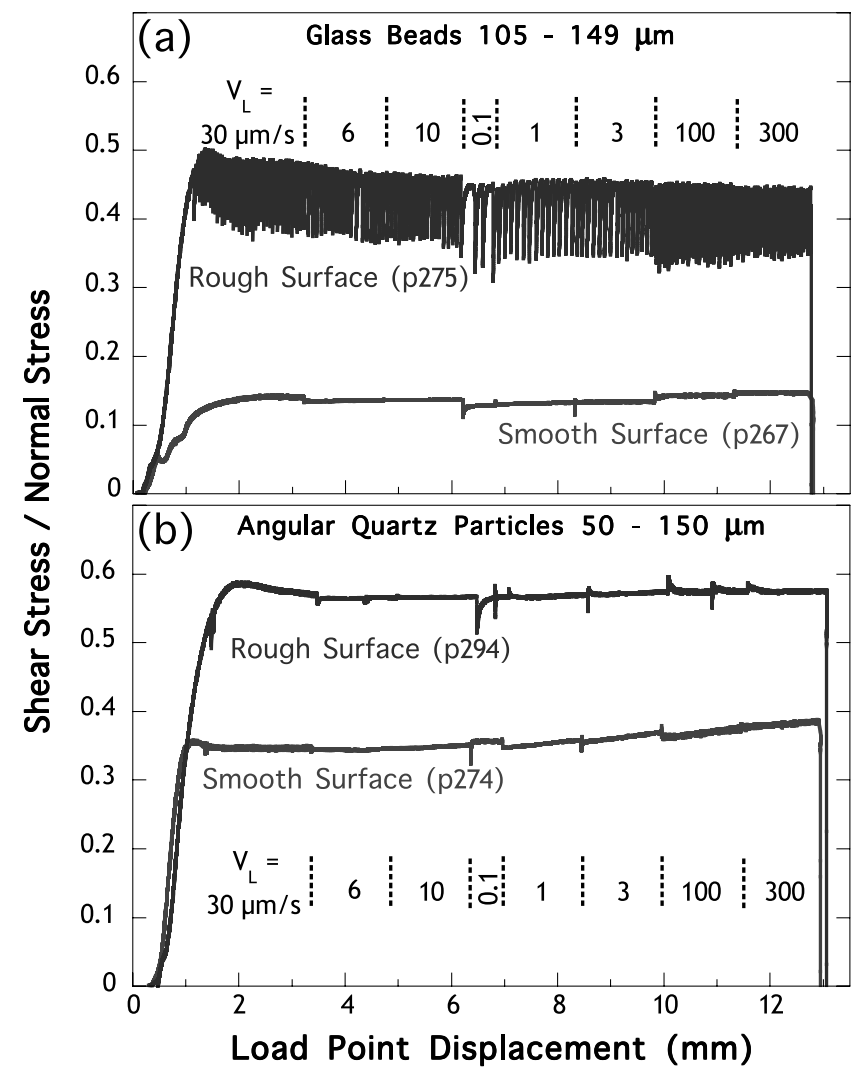

Figure 3. Coefficient of friction as a function of load point displacement. Here $\sigma_{n}=5 \mathrm{MPa}$. Each plot shows two experiments that compare grain boundary sliding (smooth surface) with pervasive shear (rough surface). Loading velocity is varied throughout the experiment. (a) Comparison of experiments consisting of smooth glass beads $105-$ $149 \mu \mathrm{m}$. Note the stick-slip instabilities that occur when the gouge is sheared between rough surfaces. (b) Comparison of experiments consisting of rough angular quartz grains $50-150 \mu \mathrm{m}$. Sliding is stable in both cases. 


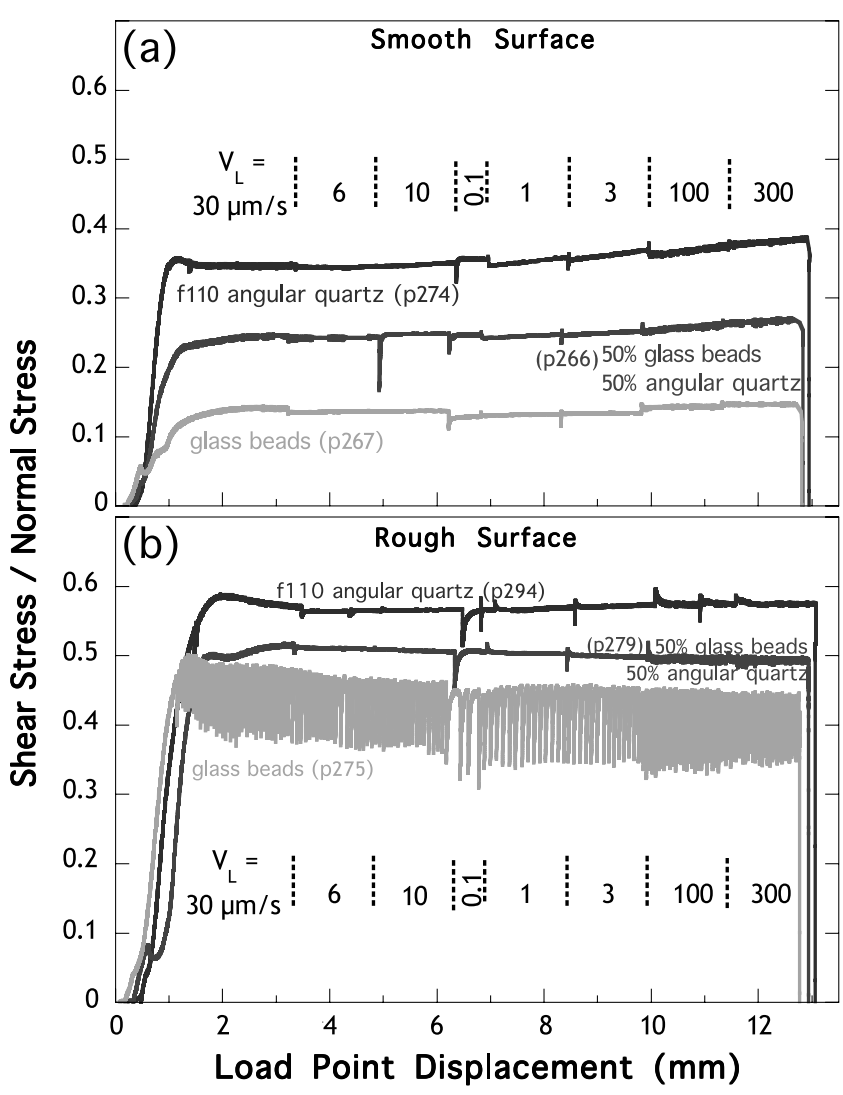

Figure 4. Coefficient of friction as a function of load point displacement. Here $\sigma_{n}=5 \mathrm{MPa}$. Both plots show that as more angular grains are mixed with smooth glass beads, frictional strength increases. (a) Increase in coefficient of friction for smooth surface experiments. Sliding is stable in all cases. (b) Increase in coefficient of friction for rough surface experiments. Stick-slip instabilities occur when beads are sheared between rough surfaces.

servo-controlled load feedback mechanism (with a $0.1 \mathrm{kN}$ resolution). The center block is forced between the two stationary side blocks by a servo-controlled ram at a constant displacement rate (with $0.1-\mu \mathrm{m}$ resolution). The position and applied force of each ram are recorded continuously at $10 \mathrm{kHz}$ and averaged to sampling rates between 1 and $1000 \mathrm{~Hz}$.

\subsection{Bounding Surfaces}

[7] The rigid forcing blocks are constructed from hardened steel with side blocks of dimensions $10 \times 10 \times 2 \mathrm{~cm}^{3}$ and a center block of dimensions $10 \times 15 \times 3 \mathrm{~cm}^{3}$. A constant contact area of $10 \times 10 \mathrm{~cm}^{2}$ is maintained throughout the experiment. Roughened surfaces were triangular grooves $0.8 \mathrm{~mm}$ deep and $1 \mathrm{~mm}$ wavelength that were cut perpendicular to the shear direction. These promote a transition from distributed, pervasive shear to progressively localized shear as a function of increasing net strain. Smooth surfaces were mirror-finished hardened steel and were used to promote and isolate grain boundary sliding.

\subsection{Gouge Composition}

[8] A leveling jig was used to construct gouge layers ranging from 2 to $8 \mathrm{~mm}$ thick, consisting of smooth glass beads, rough sand particles, or mixtures of both (Table 1). The precision glass spheres (Figure 2a) were purchased from Mo-Sci Corporation, Rolla, Missouri. We report on particle sizes that range from 53 to $597 \mu \mathrm{m}$ in diameter. The soda-lime glass beads have been studied previously in friction experiments [Frye and Marone, 2002a; Mair et al., 2002]. The rough sand grains (Figure 2c) are Ottawa sand, F110 from the U.S. Silica Company. F110 is a pure quartz sand $\left(99.8 \% \mathrm{SiO}_{2}\right)$ with minor amounts of $\mathrm{Fe}_{2} \mathrm{O}_{3}$, $\mathrm{Al}_{2} \mathrm{O}_{3}(<0.1 \%$ each), and other oxides. Particles are subangular, and the size distribution is as follows: $8 \% 53-$ $75 \mu \mathrm{m}, 25 \%$ 75-106 $\mu \mathrm{m}, 44 \% 106-150 \mu \mathrm{m}, 18 \% 150-$ $212 \mu \mathrm{m}$, and $4 \% 150-212 \mu \mathrm{m}$, with $<1 \%$ beyond the upper and lower limits. Previous laboratory experiments using Ottawa sand include those by Scott et al. [1994], Karner and Marone [1998], Richardson and Marone [1999], Mair and Marone [1999], Mair et al. [2002], and Frye and Marone [2002b]. Gouge layer mixtures of glass beads and angular sand (Figure 2b) were measured by percent weight.

[9] We studied several grain size ranges of spherical glass beads as well as varying gouge layer thicknesses to determine their effects on stick-slip instability (Table 1). Several experiments focused on a narrow particle size range of $47 \mu \mathrm{m}( \pm 4 \mu \mathrm{m})$ at a constant layer thickness. In others, we varied the thickness of layers composed of a single grain size range to systematically focus on the number of grains across the layer.

\subsection{Experiment Conditions}

[10] We conducted experiments at normal stresses of 5 and $10 \mathrm{MPa}$, a nonfracture loading regime where sliding friction for smooth spherical particles is measurably lower than for rough angular particles [Mair et al., 2002]. The layers were sheared at loading rates between 0.1 and $3000 \mu \mathrm{m} / \mathrm{s}$ at room temperature and under controlled humidity (Table 1). For controlled humidity runs, gouge particles were baked for 1 hour at $100^{\circ} \mathrm{C}$ to remove moisture. Then once the sample was quickly constructed, it was enclosed in a plastic membrane along with a

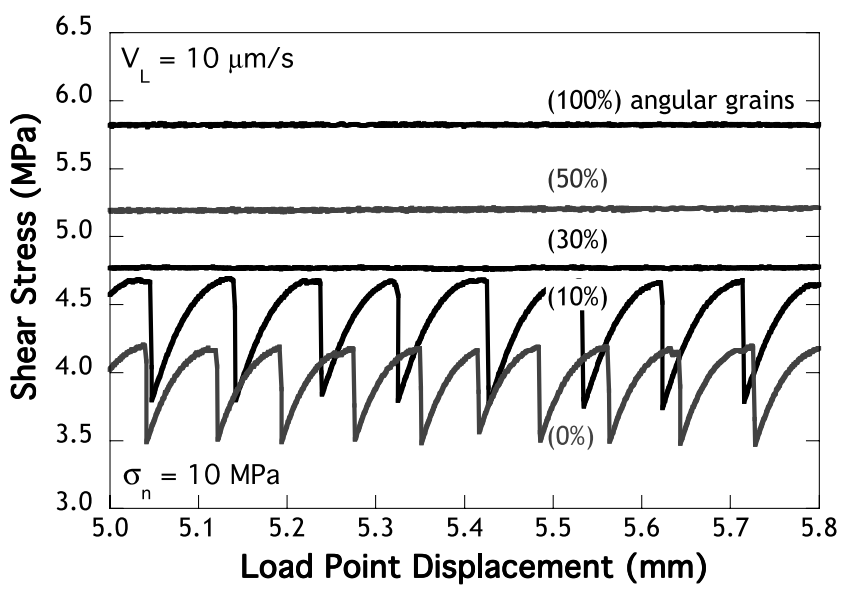

Figure 5. Shear stress data taken from sections of experimental data where the loading rate is $10 \mu \mathrm{m} / \mathrm{s}$. Here $\sigma_{n}=10 \mathrm{MPa}$. Frictional strength increases with increasing abundance of angular grains. There is a transition from unstable, stick-slip behavior ( $0 \%$ and $10 \%$ angular grains) to stable sliding ( $30 \%$ angular grains and above). 

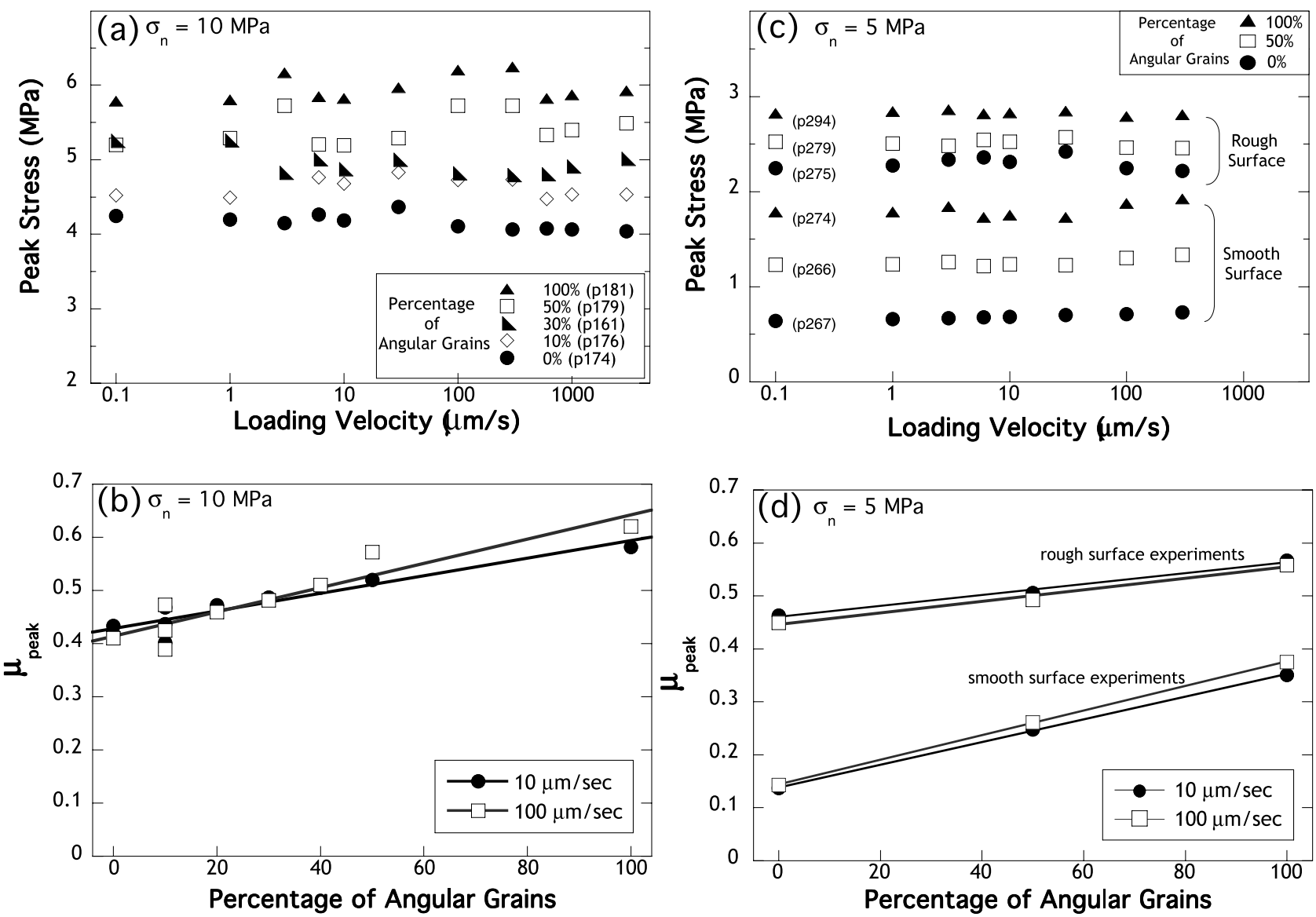

Figure 6. Average peak stress and peak coefficient of friction as a function of loading velocity and percentage of angular grains. (a) Average peak shear stress plotted as a function of velocity for gouge sheared between roughened surfaces. Here $\sigma_{n}=10 \mathrm{MPa}$. (b) Peak coefficient of friction as a function of percentage of angular grains for gouge sheared between roughened surfaces. (c) Comparison of the average peak shear stress as a function of loading velocity for gouge sheared between rough and smooth surfaces. Here $\sigma_{n}=5 \mathrm{MPa}$. (d) Peak coefficient of friction as a function of percentage of angular grains.

desiccant and hygrometer. Samples were placed in the controlled humidity membrane 12 hours prior to testing to allow equilibration at the target humidity.

\section{Data and Observations}

[11] Layers were sheared using a computer-controlled displacement history. In general, shear stress increased to a peak value followed by a brief interval of weakening before reaching a steady state frictional level (Figure 3). After initial loading at constant driving velocity, we ran velocity step tests to assess second-order changes in frictional properties of the granular layers. The loading history included an initial rate of $30 \mu \mathrm{m} / \mathrm{s}$ followed by step changes to $6,10,0.1,1,3,100$, and $300 \mu \mathrm{m} / \mathrm{s}$, respectively, for a total displacement of $12.6 \mathrm{~mm}$ (Figure 3 ). The loading history was identical for all experiments except those at higher velocities $(600,1000$, and $3000 \mu \mathrm{m} / \mathrm{s})$, which incorporated an additional $6.2 \mathrm{~mm}$ of displacement, for a total of $18.8 \mathrm{~mm}$.

[12] After the initial strength transient associated with loading, sliding friction reached a steady state level that varied slightly with loading rate. The drops in shear stress, seen at $6.4 \mathrm{~mm}$ and $8.2 \mathrm{~mm}$ displacement, were produced by brief periods in which we stopped loading (the vertical ram was stopped) in order to reset the displacement transducer and computer control files.

\subsection{Effect of Surface Roughness and Grain Angularity}

[13] Frictional strength varies systematically with surface roughness and gouge particle angularity (Figures 3 and 4). We compare the frictional strength and stability of angular and spherical particles that are sheared between smooth bounding surfaces and rough bounding surfaces. Friction for shear between smooth surfaces $(\mu \sim 0.12$ and 0.35 for spherical and angular particles, respectively) is notably lower than rough surfaces $(\mu \sim 0.45$ and 0.57 for spherical and angular particles, respectively) (Figure 3). There is a strain-hardening trend for both spherical and angular grains sheared between smooth surfaces. For both smooth and rough surfaces the coefficient of friction increases systematically as the percentage of angular particles increases (Figure 4). In addition, gouge sheared between smooth surfaces always exhibits stable sliding whereas spherical particles sheared between rough surfaces exhibit unstable, stick-slip behavior (Figure 3a and Figure 4b) consistent with previous work [Mair et al., 2002]. 

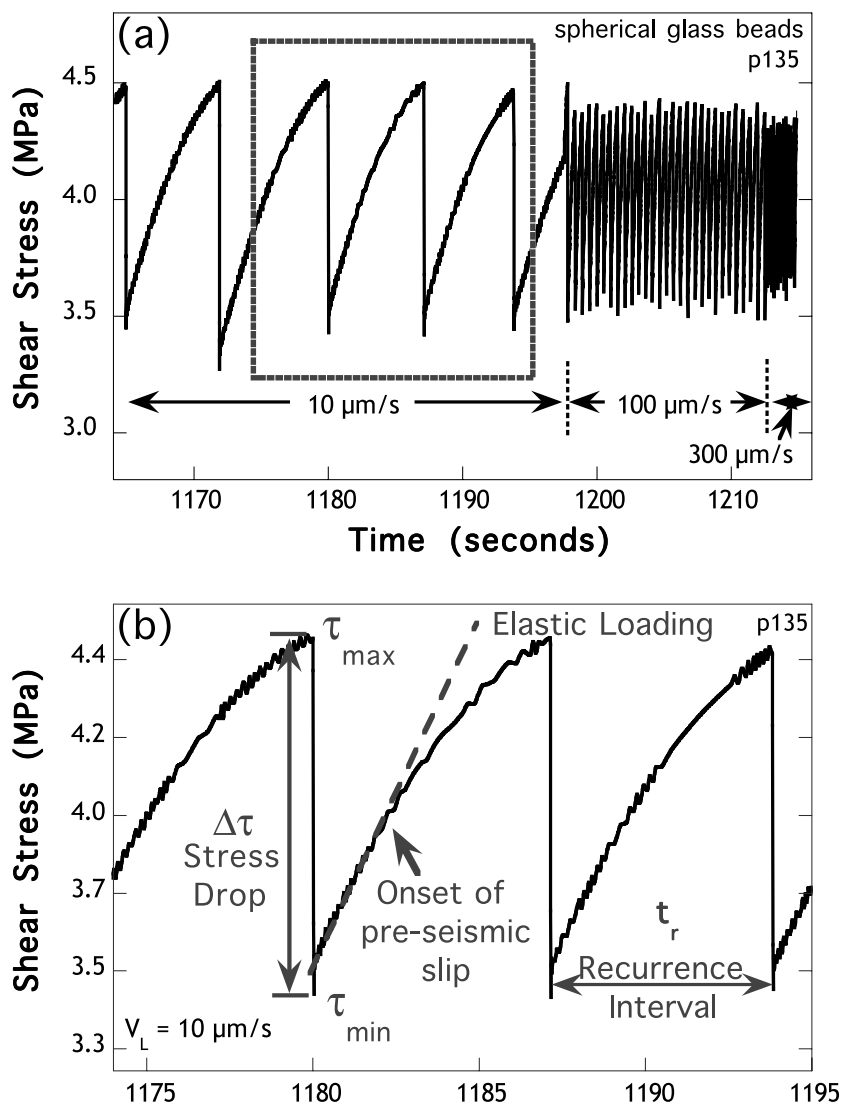

Figure 7. Shear stress data from a typical section of experimental data. Here $\sigma_{n}=10 \mathrm{MPa}$. (a) Loading rates of 10,100 , and $300 \mu \mathrm{m} / \mathrm{s}$. Data show repeated stick-slip events with velocity-dependent variations in stick-slip amplitude and frequency. (b) Enlargement of boxed region in Figure 7a. Note that stress rises linearly initially and that creep and preseismic slip begin well before failure.

[14] We measured peak shear stress in each experiment and found that it increased with the mean angularity of gouge particles (Figures 5 and 6). Figure 5 shows shear stress plotted from sections of experimental data where the loading velocity is $10 \mu \mathrm{m} / \mathrm{s}$. Each of the five lines corresponds to a given mean gouge angularity. Gouge layers that contain a higher percentage of angular grains have higher frictional strength. There is also a progression from unstable, stick-slip behavior (in gouge consisting primarily of smooth, spherical particles) to stable sliding (in gouge that consists of $\geq 30 \%$ angular grains). Frictional strength is affected by particle angularity and the roughness of the bounding surfaces, and shear strength is relatively insensitive to loading velocity over the range $0.1-3000 \mu \mathrm{m} / \mathrm{s}$ (Figures $6 a$ and $6 c$ ). Figures $6 b$ and $6 d$ show that the coefficient of friction increases linearly with increasing gouge angularity for the two loading rates that we studied in detail.

\subsection{Stick-Slip Instability}

[15] Gouge layers composed of smooth, monodisperse particles exhibit repetitive, stick-slip failure. Figure 7 shows a typical section of data from an experiment with dynamic instability (see also Figures 3 and 4). Consistent with the results of Figure $6 \mathrm{c}$, the peak failure strength is comparable at all loading rates; however, the magnitude and frequency of the stick-slip instabilities vary systematically with loading velocity. As the loading velocity is increased from 10 to $100 \mu \mathrm{m} / \mathrm{s}$, stick-slip instability becomes more frequent and the stress drop decreases (Figure 7). Figure 7b emphasizes the shape of each stick slip, which is characterized by a period of linear elastic loading followed by inelastic creep (which we refer to as preseismic slip) and a sudden drop in stress. The stress drop occurs within $<1 \mathrm{~ms}$ and is accompanied by a loud, audible signal. Figure 8 plots slip across the gouge layer, corrected for elastic distortion of the testing machine, as a function of time for the same section of data in Figure 7. The elastic correction removes deformation of the biaxial testing apparatus and forcing blocks. During repetitive stick slip the average slip rate matches the imposed driving velocity (Figure 8). We compare the slip during dynamic instabilities (coseismic slip) with the amount of preseismic slip (inelastic creep) prior to failure as illustrated in Figure $8 \mathrm{~b}$. Preseismic slip is negligible for about the first third of the stick-slip recurrence interval and then accelerates as stress approaches the failure strength. For smooth glass beads, preseismic slip is approximately equal in magnitude to coseismic slip during a given stickslip recurrence interval.
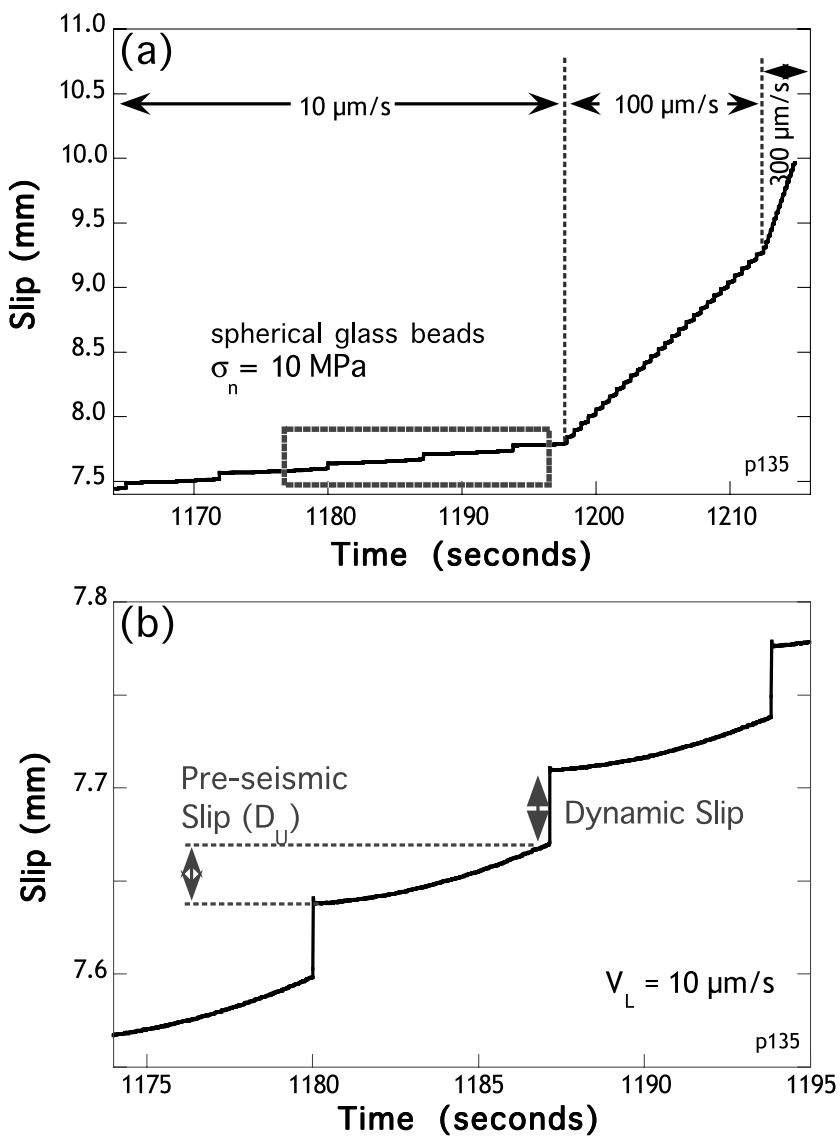

Figure 8. Cumulative slip across the shear surface plotted as a function of time. Here $\sigma_{n}=10 \mathrm{MPa}$ (the same section of data is shown in Figure 7). (a) Different slopes associated with varying loading velocities and the "steps" that occur as stick-slip sliding takes place. (b) A blowup of one of the "steps" showing how preseismic slip $\left(D_{u}\right)$ is measured. 
[16] We compare the magnitude of the dynamic stress drop $(\Delta \tau)$, the amount of preseismic slip $\left(D_{u}\right)$, the time between slip events $\left(t_{r}\right)$, and layer compaction during failure $(\Delta h)$ as a function of loading velocity, gouge layer thickness, and particle size distribution. Stress drop, preseismic slip, and recurrence interval decrease logarithmically with increasing loading velocity (Figures 9 and 10). Figure 9 shows stress drop, recurrence interval, and preseismic slip as a function of loading velocity for three experiments with

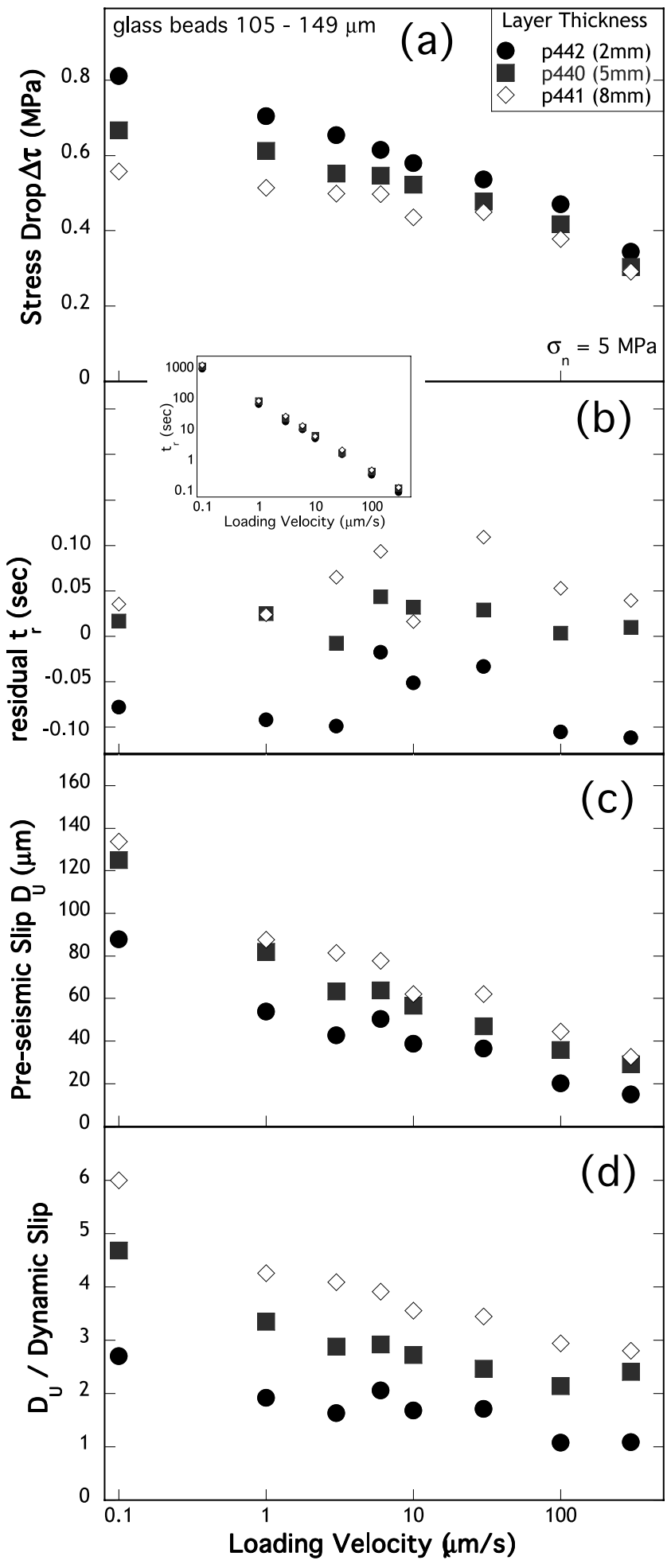

a range of initial gouge layer thicknesses. At a given loading velocity, stress drop decreases while preinstability creep increases with increasing thickness (Figure 9). Thicker layers exhibit larger preseismic slip than thinner layers for a given velocity. Our data show that preseismic slip is larger than dynamic slip, particularly for thicker gouge layers. The ratio of preseismic slip to dynamic slip ranges from 3 to 6 for the 8 -mm-thick layers and 1 to 3 for the 2 -mm-thick layers. For each layer thickness the normalized preseismic slip is larger for lower sliding velocities.

[17] We show the logarithm of recurrence interval versus the logarithm of loading velocity (Figure $9 \mathrm{~b}$ inset) along with the residual formed by removing a trend of the form $\log \left(t_{r}\right)=m \log (v)$, where $m$ is -1.0 . The plot of residual recurrence interval shows that thicker layers have longer stick-slip recurrence intervals (Figure 9b). Figure 10 shows data for four experiments where the grain size range is varied while the gouge thickness is constant at $3 \mathrm{~mm}$. In general, stress drop is smaller for smaller particles (Figure 10a); however, the data indicate some scatter for intermediate size ranges. Gouge layers composed of smaller particles also show shorter recurrence intervals and smaller preseismic slip (Figure 10) within the scatter. For these data the ratio of preseismic slip to dynamic slip ranges from 0.75 to 2.25 for the smallest particles and from 0.25 to 0.75 for the largest particles. For each particle size the normalized preseismic slip is larger for lower sliding velocities in accord with the data of Figure 9.

[18] We compare the amount of compaction during dynamic stress drop for a range of loading velocities. Figure 11 shows the relationship between shear stress and layer thickness as a function of displacement during stick-slip failure. The initial gouge layer was just over $3 \mathrm{~mm}$ thick and geometrically thinned as the layer was sheared. Figure $11 \mathrm{~b}$ provides detail of the dynamic compaction and interseismic dilation. The layer compacts with each successive stress drop, and dilation between stick-slip events is smaller in magnitude, resulting in net layer thinning with shear displacement. Dynamic compaction is larger for thicker layers (Figure 12) and decreases logarithmically with increasing loading velocity. Figure 12a shows layer compaction as a function of loading velocity for three gouge layer thicknesses. Figure $12 \mathrm{~b}$ shows dynamic compaction

Figure 9. Stress drop, residual recurrence interval, preseismic slip, and ratio of preseismic slip to dynamic slip as a function of loading velocity. Here $\sigma_{\mathrm{n}}=5 \mathrm{MPa}$. We compare experiments with varying gouge layer thicknesses. (a) Comparison of stick-slip events at a range of loading velocities showing that stress drop decreases logarithmically with loading velocity. Thinner gouge layers have a greater stress drop. (b) Residual recurrence interval, which is the difference between the predicted $\log t_{r}$ and the actual $\log t_{r}$. Thicker gouge layers have a longer recurrence interval. Inset shows recurrence interval $\left(t_{r}\right)$ as a function of loading velocity. (c) Logarithmic decrease of preseismic slip with loading velocity. Thicker layers undergo more creep before failure. (d) Logarithmic decrease of the ratio of preseismic slip to dynamic slip with loading velocity. Preseismic slip is larger than dynamic slip, particularly for thicker gouge layers. 
for 3-mm-thick layers composed of varying grain sizes. The data show no apparent relationship between grain size and dynamic compaction.

\section{Discussion}

\subsection{Frictional Strength}

[19] We observe systematic changes in the frictional strength and stability of granular fault gouge as a function of grain angularity, loading velocity, particle size, layer

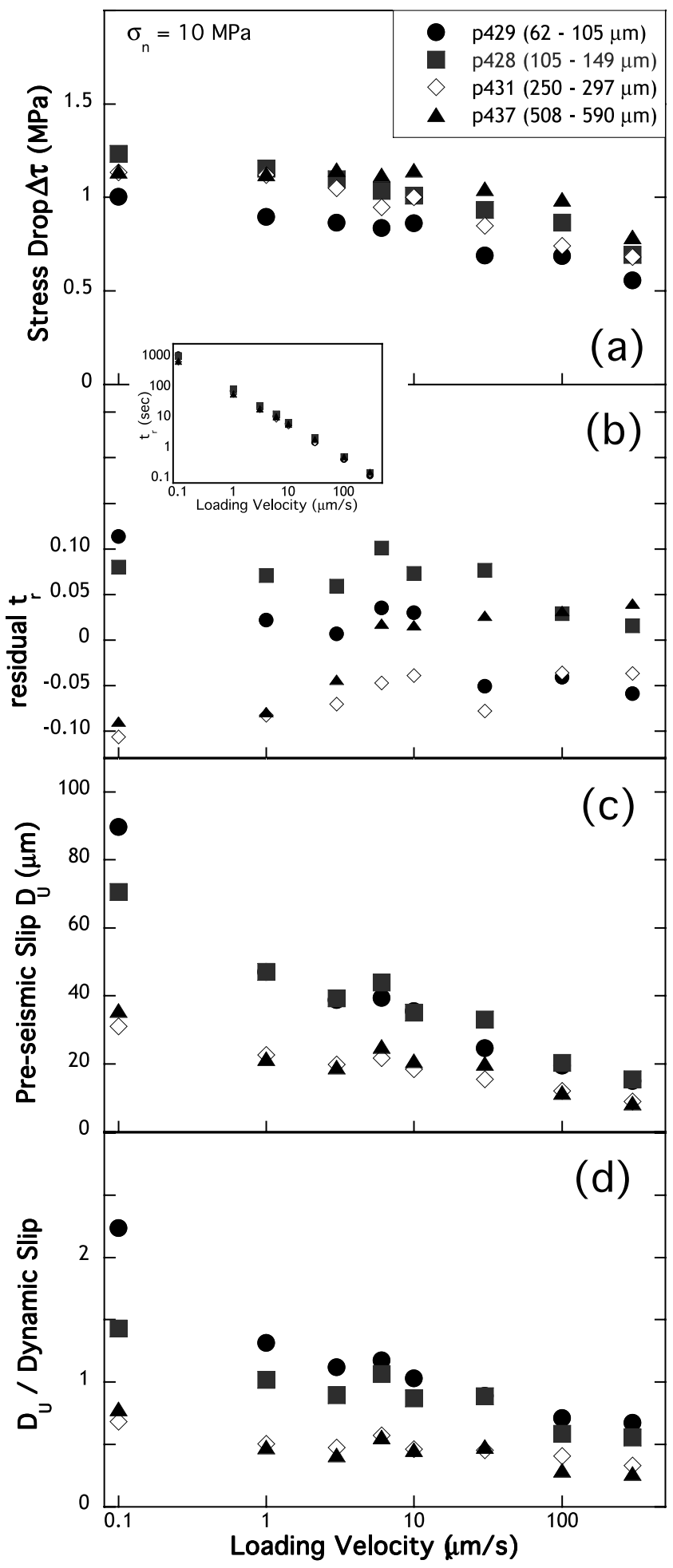

thickness, and bounding surface roughness. Our laboratory observations can be interpreted in terms of grain-scale deformation mechanisms and mechanics of shearing in fault gouge. Particle size, shape, and roughness affect the way that grains accommodate strain. Figure 13 is a schematic diagram that illustrates our interpretation of the main granular deformation mechanisms. We focus on factors that influence contact mechanics for individual particle-particle contact junctions and the processes that lead to manyparticle interactions, which give rise to the unique properties of granular materials including force chains and jamming. Our interpretations are based solely on the above macroscopic measurements, which do not include direct observations of force chains or particle contact mechanics.

\subsubsection{Surface Roughness}

[20] Figures 13a and 13b illustrate spherical glass beads and angular particles slipping along smooth bounding walls, respectively. We hypothesize that this case results in predominantly grain boundary sliding at or near the bounding surface and that rolling is minimal. Jensen et al. [1999] used the discrete element method (DEM) to numerically model particulate media sheared between roughened and smooth boundaries. They found that if a shearing surface is sufficiently smooth, the shear strength is reduced to a simple frictional sliding problem between the particle mass and the smooth surface. In a related study, Morgan [1999] showed that the abundance of rolling particles is small during localized slip. Apparently, grains along the boundary slide and rotate while grains deep within the gouge layer behave as spectator grains that experience negligible slip [e.g., Losert et al., 2000].

[21] Our data show that friction is significantly lower in the smooth boundary condition case compared to shear between rough forcing blocks and that particle roughness has a significant effect on frictional strength for a given bounding roughness. Gouge layers composed of spherical glass beads exhibit lower friction than those that contain angular particles (Figure 4). This is consistent with a lack of geometric incompatibility and associated granular jamming, as smooth particles move past one another via grain boundary sliding and rotation with little resistance. Angular particles cannot readily slide past one another and become

Figure 10. Stress drop, residual recurrence interval, preseismic slip, and ratio of preseismic slip to dynamic slip as a function of loading velocity. Here $\sigma_{n}=10 \mathrm{MPa}$. We compare experiments with varying grain sizes. (a) Logarithmic decrease of stress drop with loading velocity. Gouge layers consisting of larger grains have a larger stress drop. (b) Logarithmic decrease of recurrence interval with loading velocity. The residual recurrence interval is the difference between the predicted $\log t_{r}$ and the actual $\log t_{r}$. Layers with smaller grains have more time between slip events. Inset shows recurrence interval $\left(t_{r}\right)$ as a function of loading velocity. (c) Logarithmic decrease of preseismic slip with loading velocity. Layers with smaller grains show greater amounts of preseismic slip. (d) Logarithmic decrease of ratio of preseismic slip to dynamic slip with loading velocity. Preseismic slip is larger than dynamic slip in gouge layers composed of relatively small particles sheared at slow loading rates. 

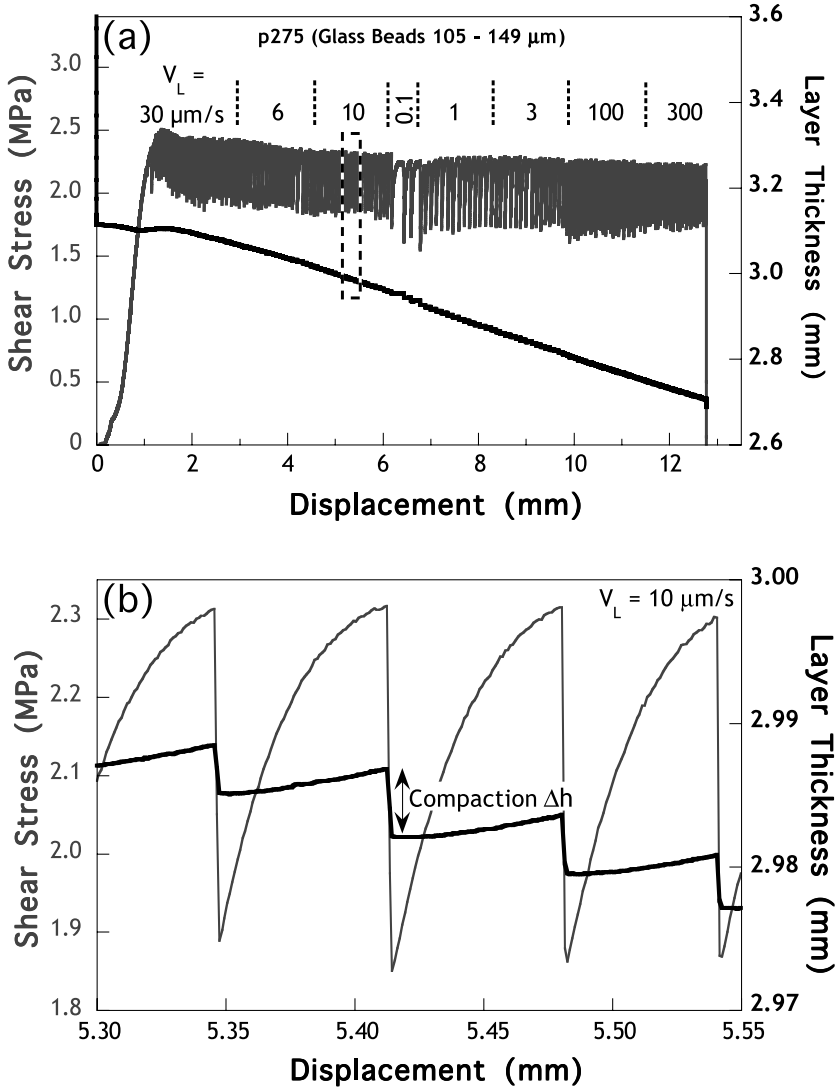

Figure 11. Shear stress and gouge layer thickness as a function of displacement. Here $\sigma_{n}=5 \mathrm{MPa}$. (a) Entire experiment and the geometric layer thinning that occurs as the gouge is sheared. (b) Enlargement of boxed region in Figure 11a where the loading velocity is $10 \mu \mathrm{m} / \mathrm{s}$. We measure the compaction of the gouge during the slip event.

locked as rotation is inhibited by roughness of neighboring particles, resulting in higher frictional strength (e.g., Figures 3 and 4). This would suggest that deformation initiates along the layer boundaries and penetrates into the shear zone, resulting in modest dilation.

[22] Our data show the degree to which friction of rough surfaces is greater than that of smooth surfaces, consistent with previous work [Biegel et al., 1989; Jensen et al., 1999]. Figures $13 \mathrm{c}$ and $13 \mathrm{~d}$ are schematic illustrations of spherical and angular gouge material, respectively, sheared between rough surfaces. These data suggest that as the shearing surface roughness increases, the layer of maximum average particle rotation moves farther from the shearing surface [Jensen et al., 1999]. In our experiments the grooved surfaces capture a layer of grains and allow slip to localize along shear bands adjacent to this layer. As slip becomes more localized with increasing displacement (partly due to geometric thinning), velocity weakening frictional behavior is observed, whereas smooth surfaces exhibit velocity weakening almost from the onset of the experiment [Marone et al., 1992; Sammis and Steacy, 1994; Beeler et al., 1996]. Additionally, as shear stress increases, particles self-organize to form force chains that carry the shear traction [e.g., Sammis et al., 1986; Geng et al., 2003]. Force is carried by a complex series of anastamosing chains of differing size and extent [e.g., Liu et al., 1995]. For the purposes of this study we focus on the major chains and generalize their distribution throughout the assemblage.

\subsubsection{Grain Angularity}

[23] Our data indicate that the coefficient of friction is significantly higher for rough, angular particles compared with smooth particles and that for mixtures of both particles, there is a systematic increase in frictional strength as a function of angular grain fraction. Numerous studies in granular mechanics support these observations [Jensen et al., 1999; Mueth et al., 2000; Albert et al., 2001; Geminard and Losert, 2002; Mair et al., 2002; Nouguier-Lehon et al., 2003; Guo and Morgan, 2004]. This response can be credited to the roughness and shape of the grains. Smooth, spherical particles accommodate strain primarily by rolling, whereas angular grains do so by dilation. The roughness of angular particles inhibits their ability to roll and increases the bulk frictional resistance as neighboring particles, and larger groups, jam and become locked. As interparticle resistance increases, particle sliding decreases and grain rotation increases [Morgan and Boettcher, 1999; Morgan, 1999]. DEM simulations show that spherical particle rotation is nearly twice that of an angular cluster of grains [Jensen et al., 1999] and that the smallest particles accommodate the greatest rotations [Morgan and Boettcher, 1999; Morgan, 1999]. Mueth et al. [2000] find a greatly reduced
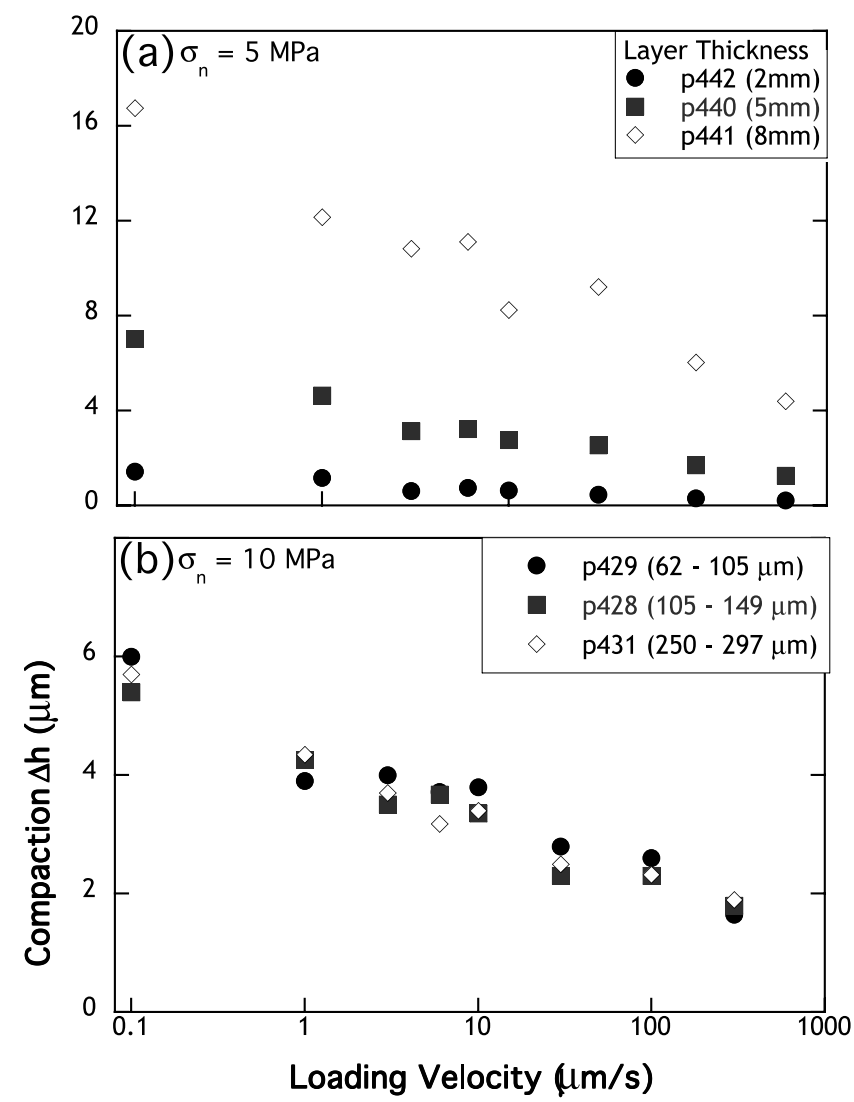

Figure 12. Compaction as a function of loading velocity. (a) Comparison of compaction during failure between experiments with different gouge layer thicknesses. Here $\sigma_{n}=5 \mathrm{MPa}$. (b) Comparison of compaction between experiments with different grain sizes. Here $\sigma_{n}=10 \mathrm{MPa}$. 
(a) Smooth Boundary Spherical Grains

Grain-boundary sliding, rolling

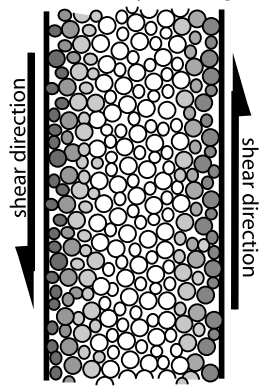

(c) Rough Boundary Spherical Grains

Force chains build and fail

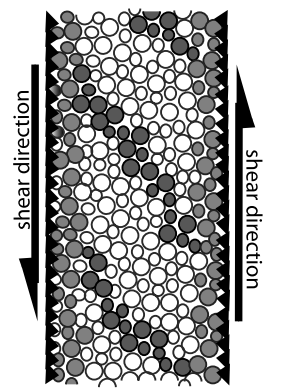

(b) Smooth Boundary Angular Grains

Grain-boundary sliding, rotation

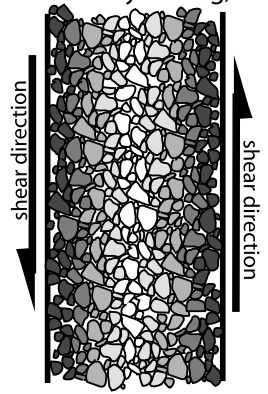

(d) Rough Boundary Angular Grains

Grains rotate, slide, layer dilates

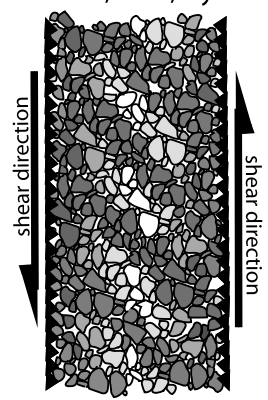

Figure 13. Schematic diagrams of spherical and angular grains sheared between smooth and rough boundaries. (a) Glass beads sheared between smooth boundaries. Shear is localized along the bounding sides. (b) Angular quartz sheared between smooth surfaces. Grains slide and rotate along bounding sides. (c) Spherical glass beads sheared between rough surfaces. A layer of grains is contained along the bounding surface, and stress is concentrated along chains of grains. (d) Angular quartz sheared between rough surfaces. A layer of grains is contained along the bounding grooves, and shear is distributed across the layer as grains rotate and slide past one another.

interparticle slip rate when smooth particles are replaced by roughened ones. The enhanced strength of the angular assemblage results from decreased rolling and increased sliding and particle jostling, which causes enhanced dilation and an increase in friction [Morgan, 1999; Jensen et al., 1999; Mair et al., 2002].

[24] We observe stick-slip instability when a gouge layer composed of $>70 \%$ spherical particles is sheared between roughened forcing blocks (e.g., Figure 5). Stick-slip behavior in sheared layers of spherical particles has been observed by several workers [Losert et al., 1999, 2000; Albert et al., 2001; Geminard and Losert, 2002], but Mair et al. [2002] found that gouge layers composed of a wide particle size distribution $(1-800 \mu \mathrm{m})$ slid stably. Mair et al. [2002] found that the particle size distribution did not influence the maximum frictional strength but that it had a significant effect on the stability of the system. On the other hand, Biegel et al. [1989] found that frictional strength decreased with an increase in the size of the largest particle within power law distributed assemblages. Our work focused on monodisperse particles, and we observed stick-slip behavior

in all cases where layers of spherical particles were sheared between rough surfaces (e.g., Figure 10). Our data indicate significant effects of grain size and layer thickness on the characteristics of dynamic, stick-slip events.

\subsection{Stick-Slip Instability and Force Chains}

[25] When a granular medium is loaded and sheared, jamming occurs when forces are localized along directional force chains [e.g., Sammis et al., 1986; Liu et al., 1995; Cates et al., 1998; Aharonov and Sparks, 1999; Morgan and Boettcher, 1999; Albert et al., 2001]. Morgan and Boettcher [1999] and Geng et al. [2003] observed that particles form force chains that are inclined about $45^{\circ}$ to the shear zone walls (parallel to the direction of $\sigma_{1}$ ). Figure 14 is a schematic illustration of a gouge layer of glass beads sheared between rough boundaries. It is important to note that we do not observe the force chains but infer how they deform on the basis of the macroscopic frictional response. We posit that a layer of grains along the bounding wall (light grey) acts together with a bridge of grains that constitute a force chain (dark grey) and spectator grains (white) that carry little to no load (Figure 14). During shear loading, force chains bear the load and begin to deform via stable creep (e.g., see preseismic slip in Figures 7 and 8) with lesser motion in unloaded regions of the assemblage (spectator grains). With continued shear, force chains become misaligned and buckle, in some cases catastrophically, causing the load to shift to more favorably oriented contacts. We suggest that force chains are relatively uniform in intensity and widely spaced in layers of monodisperse particles and that failure of one or two chains initiates slip localization, which propagates and precipitates a cascade of chain failures, resulting in dynamic, stick-slip instability of the entire layer (e.g., Figures 7 and 14).

[26] Since our experiments are performed at a normal stress below the particle fracture strength and the shearing

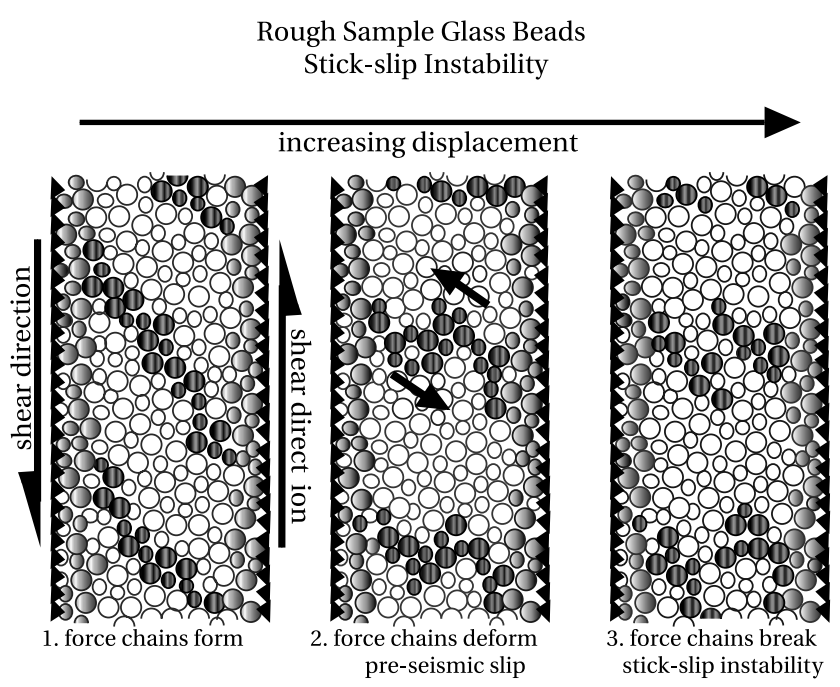

Figure 14. Schematic diagrams of spherical glass beads deforming as they are sheared between rough boundaries. Stress is concentrated along a series of force chains. As shear continues, the chains deform and eventually fail, resulting in a seismic slip event. Stick-slip instability is a result of the continuous building and breaking of the force chains. 


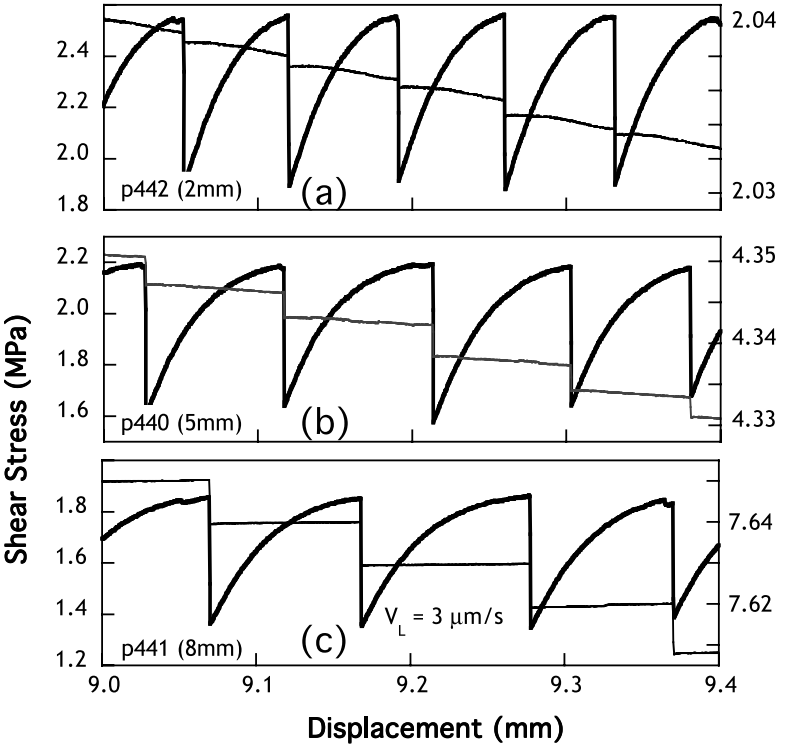

Figure 15. Shear stress and layer thickness as a function of displacement for a section of data where the loading velocity is $3 \mu \mathrm{m} / \mathrm{s}$. Here $\sigma_{n}=5 \mathrm{MPa}$. We compare the frequency and shape of the stick-slip events. Data from experiment with (a) 2-mm initial gouge layer thickness, (b) $5-\mathrm{mm}$ initial gouge layer thickness, and (c) $8-\mathrm{mm}$ initial gouge layer thickness.

surfaces are rough, we expect that slip between grains within the force chains is the most likely cause of chain failure. When a series of chains break, particles immediately reorganize to form a new set of chains that support the load. Our data indicate that grain bridges evolve subtly but continuously during shear, resulting in either stable deformation (in the case of angular particles) or repetitive stickslip behavior (when gouge material contains $<30 \%$ angular grains).

[27] Our experiments suggest that force chains exhibit qualitative differences as a function of grain angularity, and we propose the following speculative model. Force chains are expected to be three-dimensional, planar bodies in a sheared granular layer, and we take chain width as the minimum dimension of the body. We posit that force chains within angular gouge are wider and more densely spaced than chains in an equivalent layer composed of smooth particles (Figures 13c and 13d). Wider chains, composed of an interlocking set of particles (e.g., Figure 13d), would be less susceptible to catastrophic collapse than chains defined by a single set of point-to-point contacts, as suggested in Figures $13 \mathrm{~d}$ and $13 \mathrm{c}$. Moreover, more densely spaced chains would be accompanied by narrower, and thus effectively stiffer, regions of spectator grains, which would help to stabilize force chains by inhibiting buckling and misalignment.

\subsubsection{Grain Size and Layer Thickness}

[28] For rough-walled shear zones our data show that frictional strength increases as the shear zone thins and that stick-slip characteristics vary systematically with gouge layer thickness. Figure 15 shows data from identical experiments performed on three layer thicknesses. In each case the layers deform by repetitive stick-slip failure. The maximum friction is greater for the thinnest layer (Figure 15a). In addition, the magnitude of dynamic stress drop, the amount of preseismic slip, and the interevent time vary with gouge layer thickness (Figure 15). When plotted versus shear strain, the strain increment between stick-slip events is $0.019,0.013$, and 0.007 for layer thicknesses of 2,5 , and $8 \mathrm{~mm}$ loaded at $10 \mu \mathrm{m} / \mathrm{s}$, respectively. We compare the shape and frequency of the stick-slip events and find that with increasing layer thickness, preseismic slip increases,

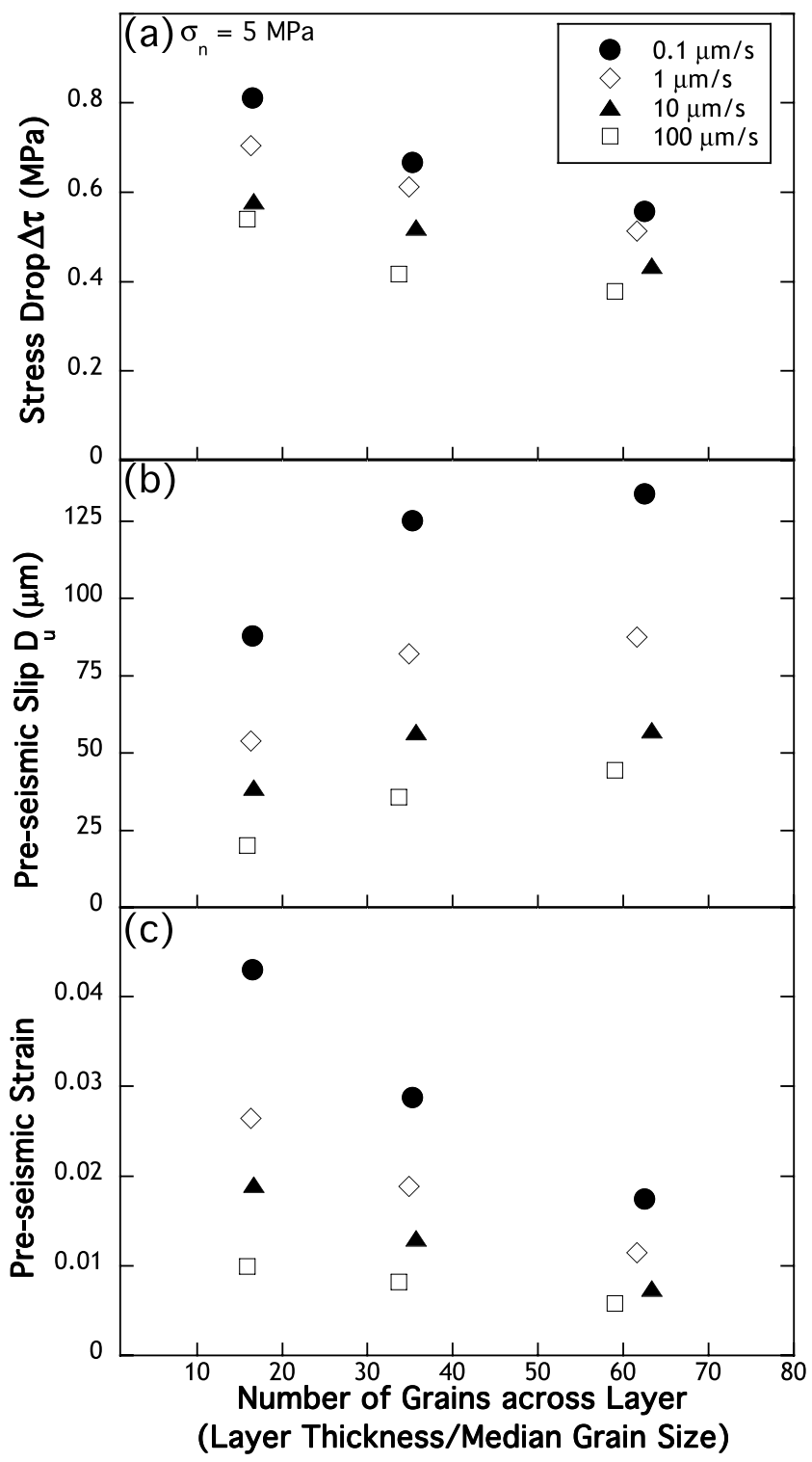

Figure 16. Stress drop, preseismic slip, and preseismic strain as a function of the number of grains across the layer (layer thickness divided by the median grain size). (a) Stress drop decreasing as the number of grains across the layer increases (i.e., thicker gouge layer). Stress drop is velocitydependent, which is also seen in Figures 9a and 10a. (b) Preseismic slip, which is greater in a thicker gouge layer. Preseismic slip is dependent on velocity (also seen in Figures 9c and 10c). (c) Preseismic strain decreasing as the number of grains across the layer increases. Preseismic strain is dependent on velocity. 


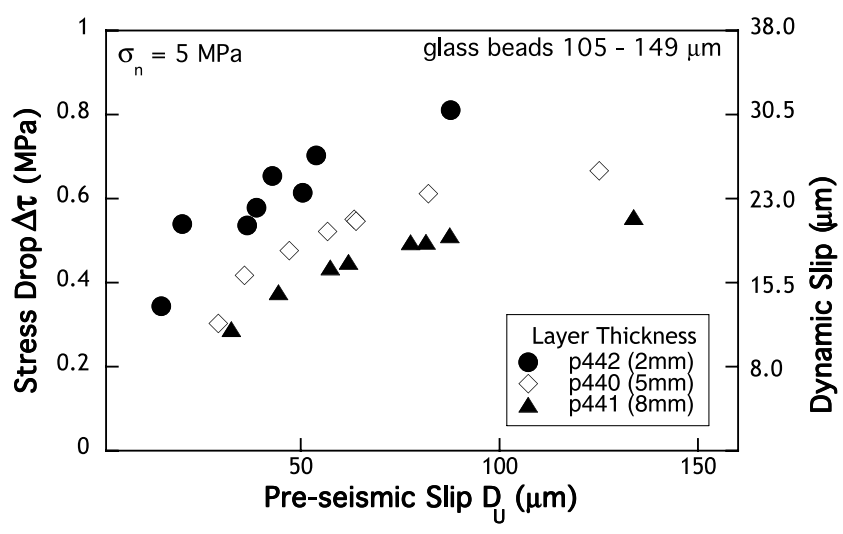

Figure 17. Stress drop as a function of preseismic slip for a series of experiments with a different initial gouge layer thickness. There is an increasing trend between preseismic slip and stress drop due to velocity dependence. The slope of the trend is greater for thinner gouge layers.

preseismic strain decreases, stick-slip frequency decreases, and stress drop magnitude decreases (Figure 16).

[29] The layer thickness and grain size effects imply that frictional behavior depends on the number of grains across the layer, or the number of grains within a given force chain. Shorter chains can support greater stress, which is consistent with a "weakest link" model, because they encompass a smaller number of potential failure points. If we look at stick-slip characteristics as a function of the number of grains across the layer, it is clear that stress drop decreases, preseismic slip increases, and preseismic strain decreases as the potential length of a force chain increases (Figure 16). These data also show a significant effect of loading velocity, with larger stress drop and larger preseismic slip at lower velocity (Figure 16).

[30] We suggest that differences in stick-slip characteristics are due to differences in brittleness of the force chains. Shorter chains can support greater load and are less brittle, as indicated by reduced preseismic strain (Figure 16). The stick-slip recurrence interval is smaller for shorter chains (Figure 15) even though the dynamic stress drop varies inversely with chain length. This is consistent with the fact that for a given stick-slip cycle, preseismic slip exceeds dynamic slip (Figure 17). The correlation between stress drop and preseismic slip is confirmed by the data shown in Figure 17.

[31] Figure 18 illustrates our model for the effect of layer thickness and chain length on the degree of brittleness. Shorter force chains can support larger average stress (e.g., Figure 15) and are less brittle than longer force chains. Dynamic layer compaction also scales with force chain length and compliance. Thicker layers or longer force chains are more compliant, which results in more preseismic slip and less dynamic stress drop (Figure 18b).

[32] Morgan and Boettcher [1999] also observed shear zone contraction when grain bridges failed and shear localized in their DEM simulations. Compaction is accompanied by grain arrangement into closer packing configurations. Lowering the density in a granular assemblage helps to create "fluidized regions" within which particles can move more readily [Losert et al., 2000]. Granular assemb- lages compact or expand in order to attain a "critical density" under a wide range of normal stresses [Aharonov and Sparks, 1999]. At low normal stresses (5 and $10 \mathrm{MPa}$ ), thicker layers have more pore space to fill as the chains collapse; thus more compaction occurs.

\subsubsection{Loading Velocity}

[33] Our results indicate a significant loading rate dependence of stick-slip instability. Stress drop, recurrence interval, preseismic slip, dynamic slip, and compaction during failure all decrease with increasing loading velocity. Force chains build and break more rapidly at increased shear rates; thus the time between slip events decreases. Our results are consistent with previous work that shows that dynamic stress drop varies with loading velocity, normal stress, recurrence interval, and effective stiffness [Karner and Marone, 2000].

[34] Our data can be explained by a model in which interparticle contact junctions strengthen with contact time. That is, at lower loading rates, time-dependent healing between grain contacts leads to increased layer strength and increased stress drop. Particle contacts strengthen with time because of chemically assisted healing mechanisms, which increase bond strength [e.g., Frye and Marone,
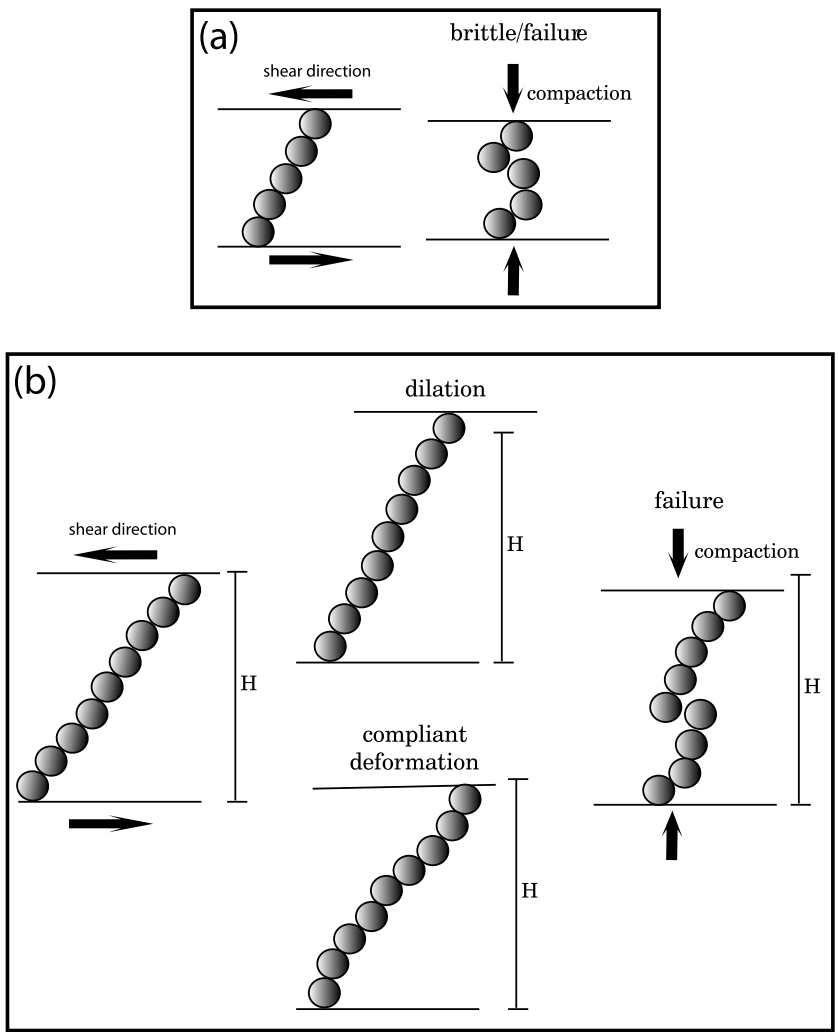

Figure 18. Comparison of deformation of single force chains within thick and thin gouge layers. (a) Force chain within a thin gouge layer (less number of grains across the layer). Chains consisting of fewer grains are less brittle. The layer compacts when the chain fails. (b) Force chain within a thick gouge layer (more grains across the layer). Chains consisting of more grains are more compliant and undergo more creep before failure. Strain can also be accommodated through dilation. Compaction occurs when the force chain breaks. 
2002b]. At higher loading rates, stick-slip recurrence interval is shorter, resulting in lesser preseismic slip (e.g., Figure 16).

\section{Conclusions}

[35] We have shown that particle characteristics (such as size, shape, and roughness) and surface roughness have a profound effect on frictional strength, stability, and particle reorganization within granular shear zones. We find that particle angularity and surface roughness increase the frictional strength and distribution of stress within sheared layers. Our data indicate that particles self-organize to form force chains, which carry the shear traction across a gouge layer, and that force chains exhibit qualitative differences as a function of grain angularity and bounding surface roughness. For gouge layers sheared between rough surfaces the transition from unstable, stick-slip sliding to stable sliding occurs when the gouge material is composed of $<30 \%$ angular grains.

[36] For unstable sliding regimes we find that stress drop, recurrence interval, preseismic slip, and dynamic slip decrease as force chains build and break more rapidly at increased loading rates. We also observe systematic differences due to grain size and gouge layer thickness. Interseismic stable creep exceeds dynamic slip for thick gouge layers or for gouge that is composed of relatively small particles (compared to the thickness of the layer). This implies that the strength of the force chain is dependent on the number of grains across the layer or the number of grains within a given force chain.

[37] Acknowledgments. We thank K. Mair and E. Richardson for helpful scientific discussions and J. Morgan, Doug Schmitt, and an anonymous reader for their careful reviews and insightful comments. This work has been funded by National Science Foundation grants OCE 0196462 and EAR 0196570.

\section{References}

Aharonov, E., and D. Sparks (1999), Rigidity phase transition in granular packings, Phys. Rev. E, 60, 6890-6896.

Albert, I., J. G. Sample, A. J. Morss, S. Rajagopalan, A.-L. Barabsai, and P. Schiffer (2001), Granular drag on a discrete object: Shape effects on jamming, Phys. Rev. E, 64, 061303, doi:10.1103/PhysRevE.64.031303.

An, L.-J., and C. G. Sammis (1994), Particle size distribution of cataclastic fault materials from southern California: A 3-D study, Pure Appl. Geophys., 143, 203-227.

Beeler, N. M., T. E. Tullis, M. L. Blanpied, and J. D. Weeks (1996), Frictional behavior of large displacement experimental faults, J. Geophys. Res., 101, 8697-8716.

Berman, A. D., W. A. Ducker, and J. N. Isrealachvili (1996), Experimental and theoretical investigations of stick-slip friction mechanisms, in Physics of Sliding Friction, edited by B. N. J. Persson and E. Tosttati, pp. 51-67, Springer, New York.

Biegel, R. L., C. G. Sammis, and J. H. Dieterich (1989), The frictional properties of a simulated gouge having a fractal particle size distribution, J. Struct. Geol., 11, 827-846.

Biegel, R. L., W. Wang, C. H. Scholz, G. N. Boitnott, and N. Yoshioka (1992), Micromechanics of rock friction: 1. Effects of surface roughness on initial friction and slip hardening in Westerly granite, J. Geophys. Res., 97, 8951-8964

Cates, M. E., J. P. Whitmer, J.-P. Bouchaud, and P. Claudin (1998), Jamming, force chains, and fragile matter, Phys. Rev. Lett., 81, 18411844.

Chester, F. M., and J. S. Chester (1998), Ultracataclasite structure and friction processes of the Punchbowl fault, San Andreas system, California, Tectonophysics, 295, 199-221.

Chester, F. M., and J. M. Logan (1986), Implications for mechanical properties of brittle faults from observations of the Punchbowl Fault Zone, California, Pure Appl. Geophys., 124, 79-106.
Dieterich, J. H. (1978), Time-dependent friction and the mechanics of stickslip, Pure Appl. Geophys., 116, 790-806.

Engelder, J. T. (1974), Cataclasis and the generation of fault gouge, Geol. Soc. Am. Bull., 85, 1515-1522.

Engelder, J. T., J. M. Logan, and J. Handin (1975), The sliding characteristics of sandstone on quartz fault-gouge, Pure Appl. Geophys., 113, 6986.

Evans, J. P., and F. M. Chester (1995), Fluid-rock interaction in faults of the San Andreas system: Inferences from San Gabriel fault rock geochemistry and microstructures, J. Geophys. Res., 100, 13,007-13,020.

Frye, K. M., and C. Marone (2002a), The effect of particle dimensionality on granular friction in laboratory shear zones, Geophys. Res. Lett., 29(19), 1916, doi:10.1029/2002GL015709.

Frye, K. M., and C. Marone (2002b), Effect of humidity on granular friction at room temperature, J. Geophys. Res., 107(B11), 2309, doi:10.1029/ 2001JB000654

Geminard, J.-C., and W. Losert (2002), Frictional properties of bidisperse granular matter, Phys. Rev. E, 65, 041301, doi:10.1103/PhysRevE. 65.041301 .

Geng, J., G. Reydellet, E. Clément, and R. P. Behringer (2003), Green's function measurements of force transmission in 2D granular materials, Physica D, 182, 274-303, doi:10.1016/S0167-2789(03)00137-4.

Guo, Y., and J. K. Morgan (2004), Influence of normal stress and grain shape on granular friction: Results of discrete element simulations, J. Geophys. Res., 109, B12305, doi:10.1029/2004JB003044.

Jensen, R. P., P. J. Bosscher, M. E. Plesha, and T. B. Edil (1999), DEM simulation of granular media-structure interface: Effects of surface roughness and particle shape, Int. J. Numer. Anal. Methods Geomech., 23, $531-547$.

Karner, S. L., and C. Marone (1998), The effect of shear load on frictional healing in simulated fault gouge, Geophys. Res. Lett., 25, 4561-4564.

Karner, S. L., and C. Marone (2000), Effects of loading rate and normal stress on stress drop and stick-slip recurrence interval, in Geocomplexity and the Physics of Earthquakes, Geophys. Monogr. Ser., vol. 120, edited by J. B. Rundle, D. L. Turcotte, and W. Klein, pp. 187-198, AGU, Washington, D. C

Katz, O., Z. Reches, and G. Baer (2003), Faults and their associated host rock deformation: Structure of small faults in a quartz-syenite body, southern Israel, J. Struct. Geol., 25, 1675-1689.

Liu, C.-H., S. R. Nagel, D. Shecter, and S. Coppersmith (1995), Force fluctuations in bead packs, Science, 269, 513-515.

Logan, J. M., M. Friedman, N. Higgs, C. Dengo, and T. Shimamoto (1979), Experimental studies of simulated gouge and their application to studies of natural fault zones, paper presented at Conference VIII: Analysis of Actual Fault Zones in Bedrock, Natl. Earthquake Hazards Reduct. Program, Menlo Park, Calif., 1-4 April.

Losert, W., J.-C. Geminard, S. Nasuno, and J. P. Gollub (1999), Friction in sheared granular material, in Symposium on Tribology, edited by M. Robbins, pp. $12-16$, Mater. Res. Soc., San Jose, Calif.

Losert, W., L. Bocquet, T. C. Lubensky, and J. P. Gollub (2000), Particle dynamics in sheared granular matter, Phys. Rev. Lett., 85, 1428.

Mair, K., and C. Marone (1999), Friction of simulated fault gouge for a wide range of velocities and normal stresses, J. Geophys. Res., 104, 28,899-28,914

Mair, K., K. M. Frye, and C. Marone (2002), Influence of grain characteristics on the friction of granular shear zones, J. Geophys. Res., 107(B10), 2219, doi:10.1029/2001JB000516.

Marone, C. (1998), Laboratory-derived friction laws and their application to seismic faulting, Annu. Rev. Earth Planet. Sci., 26, 643-696.

Marone, C., and C. H. Scholz (1989), Particle-size distribution and microstructures within simulated fault gouge, J. Struct. Geol., 11, 799-814.

Marone, C., B. E. Hobbs, and A. Ord (1992), Coulomb constitutive laws for friction: Contrasts in frictional behavior for distributed and localized shear, Pure Appl. Geophys., 139, 195-214.

Mora, P., and D. Place (1998), Numerical simulation of earthquake faults with gouge: Toward a comprehensive explanation for the heat flow paradox, J. Geophys. Res., 103, 21,067-21,089.

Mora, P., and D. Place (1999), The weakness of earthquake faults, Geophys. Res. Lett., 26, 123-126.

Morgan, J. K. (1999), Numerical simulations of granular shear zones using the distinct element method: 2 . Effects of particle size distribution and interparticle friction on mechanical behavior, J. Geophys. Res., 104, $2721-2732$

Morgan, J. K., and M. S. Boettcher (1999), Numerical simulations of granular shear zones using the distinct element method: 1 . Shear zone kinematics and the micromechanics of localization, J. Geophys. Res., 104, 2703-2719.

Mueth, D. M., G. F. Debregeas, G. S. Karczmar, P. J. Eng, S. R. Nagel, and H. M. Jaeger (2000), Signatures of granular microstructure in dense shear flows, Nature, 406, 385-388. 
Mühlhaus, H.-B., and I. Vardoulakis (1987), The thickness of shear bands in granular materials, Geotechnique, 37, 271-283.

Nouguier-Lehon, C., B. Cambou, and E. Vincens (2003), Influence of particle shape and angularity on the behaviour of granular materials: A numerical analysis, Int. J. Numer. Anal. Methods Geomech., 27, $1207-1226$.

Reches, Z. (1988), Evolution of fault patterns in clay experiments, Tectonophysics, 145, 141-156.

Richardson, E., and C. Marone (1999), Effects of normal force vibrations on frictional healing, J. Geophys. Res., 104, 28,859-28,878.

Sammis, C. G., and S. J. Steacy (1994), The micromechanics of friction in a granular layer, Pure Appl. Geophys., 142, 777-794.

Sammis, C. G., R. H. Osbourne, J. L. Anderson, M. Banerdt, and P. White (1986), Self-similar cataclasis in the formation of fault gouge, Pure Appl. Geophys., 124, 51-77.

Scholz, C. H. (1987), Wear and gouge formation in brittle faulting, Geology, 15, 493-495.
Scott, D. R., C. Marone, and C. G. Sammis (1994), The apparent friction of granular fault gouge in sheared layers, J. Geophys. Res., 99, 72317246

Tullis, T. E. (1988), Rock friction constitutive behavior from laboratory experiments and its implications for an earthquake prediction field monitoring program, Pure Appl. Geophys., 126, 555-588.

Wong, T., and Y. Zhao (1990), Effects of load point velocity on frictional instability behavior, Tectonophysics, 175, 177-195.

J. L. Anthony, ExxonMobil Exploration Company, Business Development/NBI/Global Database, CORP-GP3-652A, 233 Benmar, Houston, TX 77060, USA. (jennifer.1.anthony@exxonmobil.com)

C. Marone, Rock Mechanics Laboratory, Department of Geosciences, Pennsylvania State University, 536 Deike Bldg., University Park, PA 16802, USA. (cjm@geosc.psu.edu) 